\title{
'Genetic resources' : an analysis of a multifaceted concept
}

Deplazes-Zemp, Anna

DOI: https://doi.org/10.1016/j.biocon.2018.03.031

Posted at the Zurich Open Repository and Archive, University of Zurich ZORA URL: https://doi.org/10.5167/uzh-160845

Journal Article

Originally published at:

Deplazes-Zemp, Anna (2018). 'Genetic resources' : an analysis of a multifaceted concept. Biological Conservation, 222:86-94.

DOI: https://doi.org/10.1016/j.biocon.2018.03.031 
This article was published as: Deplazes-Zemp, Anna. 2018. "Genetic Resources, an analysis of a multifaceted concept"Biological Conservation 222, 86-93,

doi.org/10.1016/j.biocon.2018.03.031

\title{
'Genetic Resources', an analysis of a multifaceted concept
}

\begin{abstract}
'Genetic resources' is a key concept of the Convention on Biological Diversity (CBD) and the Nagoya Protocol (NP). However, the term was coined to describe value in biodiversity and create an incentive for its protection and is thus of practical relevance for biological conservation beyond the legal context. The scope of this concept is also of interest to researchers, who may be unsure for which types of analysis they are legally and ethically expected to enter access and benefit sharing (ABS) negotiations. This article presents a biologically informed analysis, which leads to an understanding of 'genetic resources' that considers various associations and implications of this notion, such as its relation to biodiversity and the role that intellectual property rights (IPR) play in the discourse. The aim is to provide a coherent, consistent and comprehensive understanding of the concept that can integrate and explain these aspects and consider both classical and novel ways of using genetic resources. Based on the biological function of genetic resources and an analysis of how they are currently used and valued, this article argues that genetic resources are a particular type of natural resource that is informational rather than tangible. This interpretation clearly identifies utilising digital genomic sequences as a form of using genetic resources. However, the article also discusses regulatory exceptions for certain utilisations of genetic resources and it mentions the possibility of treating digital sequences as such an exception.
\end{abstract}

Keywords: biodiversity, Convention on Biological Diversity, definition of genetic resources, intellectual property, Nagoya Protocol, natural resources

Highlights

- 'Genetic resources' is a multifaceted concept with interdisciplinary connotations.

- The term 'genetic resources' refers to instrumental value in biodiversity.

- In many respects, genetic resources are different from other natural resources.

- Their biological foundation reveals the informational nature of genetic resources.

- The resource value of genetic resources lies in the information they carry.

\section{Introduction}

The term 'genetic resources' has received wide attention as a key concept in the UN Convention on Biological Diversity (CBD) and is used in the domestic legislation of the states that are parties to the CBD. In environmental politics and communication, the term is used to emphasise the instrumental value of biodiversity and to explain why we benefit from its protection and conservation. ${ }^{1}$ Moreover, ethicists refer to genetic

\footnotetext{
${ }^{1}$ E.g.: WWF "Arguments for protection"

http://wwf.panda.org/what_we_do/how_we_work/protected_areas/arguments_for_protection/

(accessed December 2017)
} 
resources, for instance, in their discussion of fair access and just distribution (e.g., De Jonge, 2011; Deplazes-Zemp, 2018; Schroeder \& Pogge, 2009). The concept also raises various legal, policy and economic questions, for instance, concerning the implementation of an access and benefit sharing (ABS) scheme for genetic resources or appropriate property regimes (e.g., Kamau Evanson \& Winter, 2009; Oberthür \& Rosendal, 2013; Ruiz Muller, 2015; Vogel, 1994). Finally, it is argued here that because the term 'genetic resources' refers to usable, useful and beneficiary aspects of living nature (the object of biology) it is important to take into account biological features and characteristics of these resources. This article reflects theoretically on the concept of 'genetic resources', with the aim of considering and combining its various interdisciplinary connotations. It is not a legal analysis that seeks to interpret and explain the concept with reference to other legal documents and decisions. Instead, it is an argumentative text that discusses and critically examines the legal context of the CBD as one example in which the term is used. The article relates this use of the term to the biological foundation of genetic resources, to an analysis of what it is that is actually been used as a resource and an analysis of different connotations with the term such as biodiversity and intellectual property rights (IPR). The aim is to present a comprehensive interpretation of the concept of genetic resources, which can consider these different elements of the analysis and which fulfils the criteria of coherence and consistency. A 'coherent interpretation' is understood as an interpretation without any logical contradictions and a 'consistent interpretation' is understood as interpreting a concept in the same way throughout time and in different situations.

While the definition of 'genetic resources' has been discussed in the policy and legal context (e.g., Ruiz Muller, 2015; Tvedt \& Schei, 2013), the biological perspective on the concept, including its biological foundation and relation to biodiversity, has not received sufficient attention so far. One aim of this article is to reinforce engagement with this concept in the biological community. Conservation biology is an ideal subdiscipline to start such a discussion for several reasons: Conservation biologists are usually familiar with the concept from the CBD, which is the international regulatory framework for biodiversity conservation. Further, due to its applications and political implications, conservation biology has a long tradition of interdisciplinary discourse. Moreover, conservation biologists work with genetic resources in the context of biodiversity and thus have fundamental and practical insights into their use and value. Finally, conservation biologists have an interest in clarifying the scope of this concept because as users of genetic resources, they are expected to enter ABS negotiations with provider states when such resources are exported. The conditions under which researchers are expected to enter ABS negotiations is not only a legal but also an ethical question. It is part of good scientific practice to consider these issues also in cases when there is no legal requirement, for instance, because the provider state is not a party to the CBD.

The article begins with a brief introduction to the historical roots of the concept.

\subsection{Historical roots of the concept}

The history of the concept 'genetic resources' can be traced back to at least the 1970s and 1980s, when it appeared in the context of agricultural plants. In a 1975 Science article entitled "Our Vanishing Genetic Resources", Jack Harlan deplored that novel trends in agriculture result in the reduction of cultivated crop varieties and highlighted the importance of collections to conserve genetic diversity (Harlan, 1975). Based on the same concerns, the International Board for Plant Genetic Resources (IBPGR) was 
founded in $1974 .{ }^{2}$ In 1983, the Food and Agriculture Organisation (FA0) of the United Nations established the Commission on Genetic Resources for Food and Agriculture, which is responsible for issues related to genetic resources in an agricultural context. These early institutional endeavours conceived genetic resources as the common heritage of mankind. ${ }^{3}$ However, the notion that genetic resources represent humanity's common heritage has been strongly criticised. Pat Mooney, for instance, argued that there was a "gene drain" from the global South towards the North, which was exploited by the latter. He writes: "The South has been donating this material in the belief that its botanical treasures form part of the 'Common Heritage' of all humanity. Meanwhile, the North has been patenting the offshoots of this common heritage and is now marketing its new varieties, at great profit, around the world" (Mooney, 1983: p3). This concern has been supported by so-called biopiracy cases, in which unauthorised companies in the North accessed genetic resources and traditional knowledge from the global South (Reid, 2009). Together with increased expectations of financial profits from genetic resources, these concerns led to a paradigm shift, whereby access to genetic resources fell under the authority of state sovereignty. ${ }^{4}$

The most influential document for the current understanding of genetic resources is the CBD, which was opened for signature in 1992. The CBD considers different types of organisms in its definition of genetic resources as: "genetic material of actual or potential value", and genetic material as: "any material of plant, animal, microbial or other origin containing functional units of heredity" (CBD, article 2). Although not explicitly mentioned in this definition, the CBD omits the genome of Homo sapiens from its scope. ${ }^{5}$ This convention takes up the discussion on who should be able to benefit from genetic resources by introducing a requirement for specific ABS procedures. During 2010, the Conference of Parties to the CBD adopted the Nagoya Protocol (NP), which established a legal framework for the implementation of ABS. The Protocol entered into force in October 2014, and had been ratified by some 100 states, as of December 2017. The NP adopts the definition of 'genetic resources' contained in the CBD and specifies: "Utilization of genetic resources' means to conduct research and development on the genetic and/or biochemical composition of genetic resources, including through the application of biotechnology as defined in Article 2 of the Convention" (NP, article 2).

The term has thus been used for several decades in different contexts. Nevertheless, its meaning is not as straightforward as this standardised use might imply, which is the starting point for the analysis at hand.

\footnotetext{
2 Today, IBPGR works under the name Biodiversity international see: http://www.bioversityinternational.org/about-us/who-we-are/history/ (accessed December 2017)

3 This was explicitly stated in "The International Undertaking on Plant Genetic Resources". See: http://www.fao.org/docrep/x5563E/X5563e0a.htm\#e.\%20plant\%20genetic\%20resources\%20(follow\% 20up\%20of\%20conference\%20resolution\%20681 (accessed December 2017).

${ }^{4}$ Annex 3 to The International Undertaking on Plant Genetic Resources: Resolution 3/91: http://www.fao.org/docrep/x5587E/x5587e06.htm\#e.\%20commission\%20on\%20plant\%20genetic\%20 resources\%20and\%20international\%20undertaking:\%20progress (accessed December 2017).

5 The exclusion of human genetic resources was the topic of several COP decisions (https://www.cbd.int/decisions/cop/ (accessed December 2017): Decision II/11 explicitly "reaffirms that human genetic resources are not included". The Bonn Guidelines (adopted in Decision VI/24) mention this explicitly in their General Provisions 1C (paragraph 9, page 2). Also, in the discussion of different options in the International Regime on Access and Benefit Sharing, "human genetic resources" are explicitly excluded when the scope of this regime is described (Decision XIII/4, Decision IX/12). Finally, when the NP was adopted at COP X (decision X/1) the parties agreed, bearing in mind decision II/11, that human genetic resources are not included.
} 


\section{Examples of using genetic resources}

The analysis of the concept of 'genetic resources' in this article sets a strong focus on the enquiry of what it is that is actually being used and valued, when we speak of using genetic resources and on the biological foundations of these resources. In the following, three key examples of using genetic resources are introduced to establish a starting point for the analysis in the subsequent chapters. As a common denominator, all of these examples refer in one way or another to biodiversity as something that is valuable and they have been discussed as typical examples of using genetic resources.

\subsection{Key example 1: Plant genetic resources for food and agriculture}

As stated above, the first discussion of genetic resources was in the context of crops. The aim of plant breeding is to improve and/or combine selected characteristics of crops. For this enterprise, the biological diversity of varieties with different properties is valuable. Breeders can draw upon these genetic resources to adapt cultivated plants to novel challenges such as climate change, which has increased the need for draughtresistant varieties of different types of staple food. In novel crop varieties, for instance, drought-resistance could be combined with other desirable traits, such as high yield or disease resistance. To facilitate the exchange of seeds or other plant tissue (germplasm) the FAO established a multilateral system which regulates the exchange of the 64 most important crops in the food sector, independently of the CBD's ABS system when they are being used in research, breeding and training. ${ }^{6}$

\subsection{Key example 2: Bioprospecting}

With the establishment of the CBD, the focus of the concept of 'genetic resources' expanded from purely agricultural plants to include other organisms. The request for fair and equitable $\mathrm{ABS}$ in the CBD seems to have been driven, to a large degree, by expectations of financial benefits from bioprospecting (Harvey \& Gericke, 2011). Bioprospecting has been defined as "the systematic search for biochemical and genetic information in nature in order to develop commercially-valuable products [...]". ${ }^{7}$ Some authors also use the term 'biodiscovery' for this type of activity (e.g., Robinson, 2014: p4). Typical bioprospecting projects screen collections of biological extracts for medically relevant samples. It has been estimated that $25-50 \%$ of marketed drugs are based on natural products (Kingston, 2011). In consequence, biodiversity appeared as the source of many other financially lucrative pharmaceuticals in the future and has resulted in high expectations in biodiversity-rich countries.

\subsection{Key example 3: Basic research with biological samples}

While the CBD and NP were drafted primarily with commercial research in mind (e.g., bioprospecting), most utilisation of genetic resources seems to take place in basic research. ${ }^{8}$ Basic research with biological samples is performed in various biological sub-

\footnotetext{
6 For more information on the FAO's Multilateral System see: http://www.fao.org/plant-treaty/areas-ofwork/the-multilateral-system/overview/en/ (accessed December 2017)

7 UNDP definition of bioprospecting: http://www.undp.org/content/sdfinance/en/home/solutions/bioprospecting.html (accessed December 2017)

8 The ratio between commercial and non-commercial utilisation of genetic resources can, for instance, be estimated from permits for access to genetic resources issued by countries with ABS regulation. Such numbers have been published for Australia, which in five years (approximately 2010-2015) was reported to have granted about 450 permits, only 10 of which included potential commercial applications
} 
disciplines such as conservation biology, botany, zoology, ecology, microbiology, and biochemistry as well as, for instance, in the medical sciences (e.g. research on pathogens) and geosciences. What such basic research projects have in common is their use of genetic resources to collect new information and generate knowledge. Even when the purpose of these projects is theoretical, with the aim of increasing scientific understanding, some information may be of practical interest for future commercial applications and lead to follow-up projects with applied or even commercial intent. It is thus impossible to draw a clear line between commercial and non-commercial research in general, although there are individual research projects that are clearly driven by commercial incentives and others that are clearly motivated only by the desire to contribute to basic research. This tight connection between basic and commercial research complicates ABS negotiations concerning genetic resources.

The following chapter examines the resource value and nature of genetic resources in these practical examples.

\section{Genetic resources as a particular type of natural resource}

This discussion of genetic resources as a particular type of natural resource starts from a broad understanding of 'natural resources', following Margaret Moore's definition of the term as "anything derived from the environment and not made by humans, that is instrumental to satisfying human wants and needs. They are part of the 'natural wealth' of the world" (Moore, 2015: p163). The two words comprising the term 'natural resources' characterise its meaning: first, 'natural resources' are a type of resources, meaning they are of instrumental value. Second, they are natural, which in this context implies that they have not been produced or designed by humans. If a product has been generated from natural resources, the latter can be understood as a natural contribution to the final product. Particularly, the second and third key examples illustrate that genetic resources are utilised as natural resources, as something derived from nature, which becomes instrumentally valuable for humans to generate profits and other benefits including scientific knowledge. In accordance with this understanding, the CBD treats genetic resources as a type of natural resource and places them under national sovereignty over natural resources (CBD, article 15).

Such a description of genetic resources as natural resources raises some interesting questions concerning domesticated crops (key example 1). Despite the expansion of the definition of genetic resources beyond crops, they remain a key part of the discussion in the field; however, are they really natural? Humans have shaped their phenotypes and genotypes through selective breeding since the Neolithic Period. Thus, humans have contributed to the current appearance and features of these crops, which gives them a non-natural component. ${ }^{9}$ In contrast, these crops are often still characterised and particularly interesting due to specific natural genes, deriving from their ancestor plants. Thus, whether we use crop genetic resources as natural resources (if we are interested in specific traits originating from natural plants) or as human products (if we are interested in a variety's unnatural combination of traits) largely depends on the particular utilisation. Therefore, if we understand the concept 'genetic resources' as referring to purely natural resources, we should use a qualifier such as

(Schindel, 2010). For Brazil, it has been reported that for the period of 2002-2013, at least $86.5 \%$ of all authorisations concerned scientific research in contrast to authorisations for bioprospecting or technological development projects (Gross, 2014: p23).

${ }^{9}$ Anthropologist Darrell A. Posey refers to a similar point when he highlights that "biogenetic resources" are often modified by human action (e.g., in Posey, 1995: pp9, 20). 
'non-natural' or 'not purely natural' in the context of crops so that we are coherent and consistent in the interpretation of the concept. Such a specification may help explain why independent regulation such as the ITPGRFA, with its multilateral system, is applied for this particular type of genetic resources. As a consequence of this peculiarity, an independent explanation may be needed for placing such non-natural genetic resources under national sovereignty.

\subsection{The non-material nature of genetic resources}

As items that are instrumental for addressing human needs and desires and are derived from nature, genetic resources are thus a type of natural resource. When we address the questions of what exactly is the resource that we are using or where is the value in the genetic resources being imported from foreign countries, we realise that there is one crucial difference from other natural resources such as ores, petroleum or timber. While in the latter examples, the material is used as a resource, in the case of genetic resources, the genetic information is the resource being used and valued. In the following, I explain this point in more detail:

The utilisation of traditional (material) natural resources such as ores, timber or petroleum depends on the material processing of these resources, be it as raw material in manufacturing procedures or as a provider of energy in a combustion process. In both cases, a constant supply of this natural resource is required to yield further benefits and profits. In contrast, our examples illustrate that utilisation of genetic resources does not depend on such material supply (see also Deplazes-Zemp, 2018). Cases of plant genetic resources in traditional crop breeding (key example 1) are closest to the classical utilisation of natural resources. One may wonder how this differs from utilising biological resources such as timber or fish; in both cases, living organisms are used as natural resources. However, in case of timber or fish, benefits and profits depend on the amount and mass of the biological resource that can be yielded; this is the same situation as for other material natural resources such as ores or petroleum. In contrast, profitable utilisation of plant genetic resources in breeding is based on singular plant traits (e.g., draught-resistance) or combinations of such traits that could be crossed into commercial varieties. The utilisation of genetic resources thus requires only one or a few samples of the original resource plant in question. Once the new trait has been introduced into the commercial variety, cultivating this new variety with the novel genetic combination in large amounts does not depend on further supply of the original genetic resource. The difference also applies to the utilisation of genetic resources in bioprospecting (key example 2). As described above, bioprospecting projects systematically search for biological samples that produce a desired effect. Once the users of this resource identify such a sample, they isolate the compound that is responsible for the effect. They then try to cultivate the plant in question ex situ or produce the compound using chemical synthesis or genetically modified microorganisms; as a result, they no longer depend on further material supply of the plant of origin. In the case of basic research with biological samples (key example 3), it also is information that is valued and exported.

The idea of the informational nature of genetic resources has been highlighted by other authors including Christopher Stone, Joseph Henry Vogel and Manuel Ruiz Muller (Ruiz Muller, 2015; Stone, 1995; Vogel, 1994). The latter two have tried in vain to bring this point of view into the CBD (Ruiz Muller, 2015). They have addressed the issue from the point of view of economists, relating genetic information to the 'economics of information' (Oduardo-Sierra, et al, 2012), and aim to understand benefits from genetic resources and how they can be turned into incentives for biodiversity conservation. A 
particular focus of these authors lies in integrating their analyses of genetic resources into an explicit model of attributing property rights (Ruiz Muller, 2015; Vogel, 1994; Vogel et al., 2011). In the article at hand, the phrase 'informational resources' is used rather than Vogel's phrase 'genetic resources as natural information' because the goal here is to emphasise the informational character of genetic resources; the question of their naturalness is discussed separately. Moreover, this article aims at explaining the particular, informational nature of genetic resources based on an analysis of how value is generated from them and with reference to their biological foundation. A conclusion about the informational nature of genetic resources has thus been drawn here, independent of the economic models suggested by Vogel, Ruiz Muller and others, but in agreement with their theoretical assumptions.

From a biological point of view, the argumentation for the informational nature of genetic resources is straightforward. The genome carries the blueprint of the organism in question in the form of DNA or RNA. The biological function of these nucleic acids lies in the information that they contain in the sequence of the four nucleobases-adenine, guanine, cytosine and thymine/uracil. 'Genetic information' is a common phrase in biology; therefore, the idea that genetic resources are informational will be intuitive for most biologists. However, it could be countered that this understanding of 'genetic resources' is too 'biologistic' and reductionist in nature. Critics could argue that long before the genome of these organisms was sequenced, or even before it was known that nucleic acids are the carriers of genetic information, genetic resources were utilised. They were exchanged as biological materials, for instance, as individual crop plants or seeds, or they were 'stolen', for example, by scientists collecting material samples of different species in the rainforest. This objection, however, cannot refute the fact that genetic resources are informational, because as explained above, the utilisation and value of these samples relies on the intangible information that they carry rather than on their material, even if it is material samples that have been collected, exported, exchanged or stolen.

\subsection{Practical consequences of the non-material nature of genetic resources}

The interpretation of 'genetic resources' suggested above contradicts the CBD's reference to material in its definition of genetic resources as "genetic material of actual or potential value". Genetic material in the sense of material nucleic acids is not of interest to users; it is always the information carried by this material that is valuable. Therefore, this definition reflects neither the real value of genetic resources nor their biological function nor how genetic resources are actually being used. To harmonise the CBD's definition of 'genetic resources' with the resource value, resource utilisation and biological foundation of this type of resource, it would be necessary to adapt the original text of the CBD such that it acknowledges the fact that the value of genetic resources lies not in their material but in sought-after information. The request for an analogous adaptation has been brought forward by Vogel and colleagues for many years but so far has not been considered (Ruiz Muller, 2015). This non-consideration can be explained pragmatically, by the argument that the COP's main priorities must lie in implementing its key objectives in light of upcoming challenges rather than renegotiating basic definitions. However, based on my previous analysis this should not be used as an excuse to ignore the fact that it is the informational value of genetic resources to which ABS applies. The purpose of this article is to raise the awareness of this important point in the biological community. While this may contribute to a revision of the definition in the CBD in the long term, in the short term, the main aim is to bring this perspective into the discussion of how the NP should be implemented in concrete cases. The pragmatic 
short-term recommendation is thus to set a stronger focus on the NP's definition of 'utilisation of genetic resources', which refers to conducting "research and development on the genetic and/or biochemical composition of genetic resources". This could serve as the starting point to harmonise regulation of genetic resources with their practical utilisation as information, in spite of inconsistencies regarding how they have been defined in the CBD.

Morton Walloe Tvedt and Peter Johan Schei suggested a similar compromise between a definition of genetic resources that refers to their material and the actual use of their information. Rather than insisting on the non-material nature, these authors refer to a broad interpretation of 'genetic material' in the CBD and NP that includes material as well as "intangible, informational elements" (Tvedt \& Schei, 2013: p21). While such an approach could be successful in bringing the consideration of the informational nature of genetic resources into the policy discussion, it is argued here that to understand the particular features of genetic resources and to integrate them into a coherent, consistent and comprehensive picture it is important to be aware of the problem with reference to material in the CBD definition.

The question of how to consider the informational nature of genetic resources is very topical in view of novel technological developments that offer new possibilities of working with genetic information. Examples of such developments are first, the utilisation of digital sequences in synthetic biology, which is currently being debated as a potential form of using genetic resources, and second, environmental DNA (eDNA), which has not yet received much attention in this context but is of particular interest in conservation biology.

\subsection{Controversial example 1: Synthetic biology}

The term 'synthetic biology' is used for different approaches aimed at introducing rational design or engineering strategies into biology (Deplazes, 2009). This discipline works with genetic material, but it is often not full genes but rather gene fragments or regulatory sequences that are of interest. Thanks to rapid technological progress in DNA synthesis, tangible genetic materials can now be synthesised based on the genetic sequence without the need to import materials from other countries. The digital code of a gene of interest is sufficient for using this genetic resource. The extent to which this handling of genetic data is covered by the NP has been critically discussed, for instance, at the $13^{\text {th }}$ UN Biodiversity Conference COP 13 in Cancun in December 2016. ${ }^{10}$ A central question was whether the NP applies only to tangible genetic materials or whether digital sequences are included (Baglay, 2015; CBD, 2008; Tvedt \& Schei, 2013). Concerns were brought forward that unauthorised use of digital sequences from genetic resources would amount to 'digital biopiracy' (ICSWGSB, 2016). The parties at the COP 13 did not come to an agreement as to how to deal with genetic fragments or digital sequences at the international level. ${ }^{11}$ Nevertheless, certain countries, for instance, Brazil, already include 'information of genetic origin' in their ABS regime (Baglay \& Rai, 2013:p20; Manheim, 2016). Likewise, the Andean Community's Common Regime on Access to

\footnotetext{
${ }^{10}$ For more information, see the summary of this conference at http://www.iisd.ca/biodiv/cop13/enb (accessed December 2017).

11 In the CBD's online Forum on Synthetic Biology, Joseph Henry Vogel initiated an interesting discussion with his criticism that the AHTEG definition of synthetic biology does not refer to the informational nature of genetic resources, which confirms that the importance of this aspect has not yet been generally acknowledged http://bch.cbd.int/synbio/open-ended/discussion/?threadid=8367 (accessed December 2017).
} 
Genetic Resources (comprising Bolivia, Columbia, Ecuador and Peru) includes 'intangible components' in their definition of access to genetic resources. ${ }^{12}$

The synthetic biology example will be discussed in light of the interpretation of genetic resources as informational natural resources after a brief introduction of the second controversial example:

\subsection{Controversial example 2: eDNA}

Research using eDNA is another example of a novel technological development that leads to new and sometimes unpredictable modes of utilising biological information. The phrase 'eDNA' describes DNA fragments that can be extracted from air, water or other environmental samples and thus without direct contact to the living organism from which they originate (Baird \& Hajibabaei, 2012). Often, these eDNA fragments have been degraded but still enable conclusions to be drawn, for instance, about the composition of organisms that lived along riversides (Deiner et al., 2016). The utilisation of eDNA may become relevant in biodiversity research (Thomsen \& Willerslev, 2015) and is thus also interesting for conservation biologists. Besides the question of how to deal with samples that are being collected detached from the original organism, this example raises similar issues as the case of synthetic biology. Again, it is not clear whether research involving sequencing results of air or water samples should count as 'utilisation of genetic resources' and thus be subject to ABS.

These two examples are controversial with respect to the question of whether genetic resources are being used in work with digital sequences. Based on a literal reading of the CBD's definition of 'genetic resources', it could be argued that the use of digital sequences should not count as using genetic resources because it does not involve biological material. However, with a focus on the NP's definition of 'utilising genetic resources', it can be reasoned that work with digital sequence is a form of conducting research on the genetic composition of genetic resources, which falls into the scope of the definition. Likewise, the interpretation of genetic resources developed in this article, according to which they are an informational type of natural resource, suggests that both controversial examples are cases of using the informational resource value of genetic resources.

However, even if we acknowledge that a coherent and consistent interpretation of the concept of 'genetic resources', as developed in this article, leads to the conclusion that research with digital sequences is a form of resource utilisation, there may be specific reasons not to include them in the regulatory ABS framework. By a specific reason I mean a reason that leads to the adaptation of a general rule to take into consideration particular practical challenges in certain situations. For instance, there are rules (in the sense of laws) for car drivers in road traffic. However, for certain specific reasons, there are exceptions to these general rules for police cars in emergency situations. As will be discussed in the next section, specific reasons can be brought forward to explain why human genetic resources are not included in the ABS framework. With respect to research on digital sequences, some specific reasons that might be brought forward to argue for exemption include the impossibility of controlling access to digital sequences and the administrative burden that would follow from a request of $A B S$ in these cases. Moreover, it might be argued that there would be negative consequences for the actual aims of the CBD with respect to biodiversity conservation, when any type of research with digital DNA libraries, for instance, in barcoding projects,

\footnotetext{
${ }^{12}$ Decision 391-Common Regime on Access to Genetic Resources, Article I: http://www.wipo.int/wipolex/en/details.jsp?id=9446 (accessed December 2017).
} 
would have to undergo ABS negotiations (see section 4.4). However, this article is not the place to scrutinize these reasons or to make any suggestions as to whether they are important and convincing enough to grant such an exception from ABS regulation.

The reader may wonder why so much emphasis is placed on the informational nature of genetic resources in this article when it eventually allows for the possibility to exclude the use of digital sequences as 'pure information' from the scope of the ABS framework for specific reasons. My motive to refer to specific reasons here is twofold. First, it is important to clarify that from the conclusion that the use of digital sequences is a form of utilising genetic resources it does not necessarily follow that they must be subject to ABS regulation. The question of what this conclusion means for the regulation of digital sequences must be discussed separately. Second, it follows from my conclusion that if the use of digital sequences is excluded from ABS regulation, this exclusion cannot be justified with the argument that digital sequences are not a form of using genetic resources. Instead, such an exception would have to be based on specific reasons, which would have to be scrutinized for their persuasiveness. If it is transparent that the exception is granted based on specific reasons, this will clarify that other requests for exceptions must be based on new and convincing specific reasons. Moreover, exceptions may be revoked in light of new specific reasons.

The aim of adhering to a coherent and consistent interpretation of the concept of 'genetic resources' is thus compatible with taking into account specific practical challenges in different types of resource use. The following chapter supports this claim with the discussion of a type of genetic resources that has generally been accepted as an exception with respect to ABS regulation.

\subsection{Genetic resources and the human genome}

As indicated earlier, ${ }^{13}$ human genetic resources have been omitted from the framework of the CBD and NP, and the term 'genetic resources' is usually applied in the context of non-human genomes. ${ }^{14}$ However, there seems to be no convincing reason why the human genome should not be considered a type of genetic resources. The human genome is not only the same with respect to its biological function and composition, but to a large extent, DNA sequences of the human genome and genomes from other organisms are identical. Human genetic resources, like other genetic resources, are used as a natural resource when lucrative products are generated in the pharmaceutical industry, for instance, genetic tests or medical treatments. Human and non-human genetic resources are thus comparable with respect to function, content and how benefits are produced. However, although human genetic resources and their utilisation are not different from other types of genetic resources, there are good specific reasons to treat this type of genetic resources exceptionally. Such reasons include differences in the disciplinary and regulatory contexts of resource use. The national and international institutions and treaties that address agriculture and environmental conservation are different from those concerned with human health, which is the context in which the human genome is of interest. Moreover, the specific relations that humans have to human genetic resources provide good reasons to treat and regulate the human genome differently from other genetic resources (Schroeder \& Lasen-Diaz, 2006). The difference between the two types of genetic resources became particularly relevant with the shift from the common heritage model to the idea of state sovereignty over genetic resources

\footnotetext{
13 See footnote 5

14 Authors who previously discussed benefit sharing from genetic resources alongside the situation of the human genome include: (Dauda \& Dierickx, 2013; Schroeder \& Lasen-Diaz, 2006; Schuklenk \& Kleinsmidt, 2006).
} 
as declared in the CBD. Speaking of sovereignty over human genetic resources does not make sense because Homo sapiens can be found in every state. Moreover, state sovereignty over individual (or subgroup) genetic variations would be highly problematic for ethical reasons, because of the particular relations of the concerned individuals to their material DNA samples and the genetic information that it contains. In the case of the human genome, an exception on specific grounds has thus been well established and illustrates that it is possible to grant exceptions. Although, or particularly, because human genetic resources are naturally treated as an exception, it is important to raise awareness of the fact that human genetic resources are just as much a type of informational natural resources as non-human ones. Therefore, it seems advisable to speak explicitly of non-human genetic resources in the context of the CBD. This clarification brings out those practical aspects, which are similar in the human and non-human contexts, for instance, the question of patentability of genetic sequences (see section 5).

\section{Genetic resources and biodiversity}

The previous chapter attempted to characterise genetic resources as an informational type of natural resource, starting from an analysis of how genetic resources are actually being used and valued and taking into account the biological function of genetic information. This chapter addresses another dimension of the concept of 'genetic resources', namely its connection to biodiversity. This important aspect has often receded into the background when the definition of 'genetic resources' is being discussed with a particular focus on the legal and economic implications. It is thus important to raise conservation biologists' awareness of the discussion of this concept hoping that this will motivate them to contribute to the discussion and give the biodiversity aspect more weight. The term 'genetic resources' was coined, after all, to demonstrate that biodiversity is instrumentally valuable and thus has resource character, as illustrated by Jack Harlan's plea in 1975 introduced above (Harlan, 1975) and the central role that this concept plays in the CBD. This chapter examines how the concept of 'genetic resources' relates biodiversity to natural resources and which specific resource characteristics result from this relation.

\subsection{Biodiversity as a natural resource}

The instrumental value or resource character of biodiversity and thus its relation to what was described in the previous chapter is not obvious. For instance, Donald S. Maier explicitly denied this relation in his provocatively titled book, "What is so good about biodiversity" (Maier, 2013). He argues, amongst other things, that the idea of a particular value of biodiversity as genetic resources is inaccurate because it is singular species and not biodiversity as a whole that serve as natural resources and provide benefits (Maier, 2013: pp163ff, 196ff). According to such an understanding, biodiversity is an accumulation of individual examples of genetic resources in the form of resourceful genes or genomes. Even in this interpretation, it can be argued, in contradiction to Maier, that biodiversity as a whole is valuable as a resource because we do not yet know the relevant genes/genomes that will be identified as instrumental in the future. This is the idea exploited in bioprospecting (key example 2), and can be found in the CBD's definition of 'biological resources', when it refers not only to their actual but also their potential value for humanity. Besides this understanding of biodiversity as a source of not-yet-identified instrumental value, there are other understandings that attribute the value to the diversity itself. In these views, biodiversity is seen as a source for future development of new combinations, new genomes, species and ecosystems, be it through 
natural evolution or technological combination. Here, it is the diversity itself that is the resource because it is the source of something new. Likewise, diversity of genetic traits allows a population or ecosystem to deal with novel challenges, which leads to the argument that biodiversity is valuable because it provides resilience. Finally, in academic projects studying interactions in and compositions of ecosystems, it is often the diversity itself, not only the individual organisms or species, which is of interest. Drawing on these interpretations, we can understand the concept of 'genetic resources' as a particular appreciation not only of the information in individual genomes but also of biodiversity in general as a natural resource. This interpretation also refers to the informational nature of genetic resources, since it is not the material in biodiversity that is of value but the plethora of information that it contains.

\subsection{The need for protection}

The connection of genetic resources to biodiversity reveals another feature, namely their particular vulnerability. Traditional natural resources can be divided into three categories: non-finite resources, such as wind or solar energy; and two forms of finite resources, namely renewable resources, such as fisheries and timber; and nonrenewable resources, such as ores, coal and petrol. Genetic resources cannot be integrated into this classification. As informational resources, they are not finite in the sense that resource stocks are depleted by overuse. However, they are destructible by means other than resource utilisation, which makes them even more vulnerable than non-renewable resources. This aspect of genetic resources is particularly prevalent in the discussion of genetic resources as biodiversity. The on-going loss of biodiversity has been deplored not only because of the loss of instrumental genetic resources but also because of the potential intrinsic value of biodiversity, as declared, for example, in the CBD, and because of the environmental consequences for humans and the rest of nature. The fact that it is, to a large degree, the industrialised human lifestyle that has triggered the on-going loss of biodiversity, could lead to environmental responsibilities that go beyond sustainable use towards active protection of biodiversity. These particular responsibilities must be taken into account in a comprehensive discussion on genetic resources, and they are the main background against which ABS for genetic resources has been integrated into the CBD. Another consequence of the need for protection in the context of genetic resources is the incurrence of opportunity costs when protection of biodiversity is accompanied by a decrease in yield for those who use land in a sustainable way or abstain from using it altogether. Ethical and policy reflections on genetic resources that aspire to comprehensiveness must consider these particular responsibilities and the occurrence of opportunity costs related to the vulnerability of genetic resources as biodiversity.

\subsection{Scientific benefits}

As a type of natural resource, genetic resources are used to create benefits. The third key example (academic research in general) and the second controversial example (eDNA) introduced earlier illustrate that basic research is one of the main utilisations of genetic resources and that research projects studying biodiversity including conservation biology studies play an important role in this context. The resulting benefits are of a different nature than benefits from classical natural resources, be it petrol, ores, diamonds, fisheries or timber, which are fungible and can be quantified by monetary substitutes. In contrast, monetary value is not usually assigned to gains from research that has not been commercialized. Scientific findings deriving from genetic resources are valuable for other researchers in the field and increases the prestige of the scientists and 
institutions involved. In addition, new information about biodiversity could be of particular interest for local people in the study area and for other societies. Finally, it is important for nature conservation projects and ideally contributes to the protection of biodiversity. In this sense, genetic resources produce different types of non-commutable benefits for different interest groups. The appendix of the NP includes a list of potential benefits from genetic resources that could be shared, which indicates that there is awareness of the special benefits that result from research on genetic resources. Again, this particularity of genetic resources with respect to the resulting benefits explains why they are different from other types of natural resource, which are utilised mainly for monetary profits.

To relate these particular features of genetic resources as biodiversity more directly to the utilisation of genetic resources and to the previous chapters, conservation biology is discussed as a biodiversity example of genetic resource use:

\subsection{Biodiversity example 1: Conservation biology}

Conservation biology is an applied science with the aim of producing scientific benefits for biodiversity conservation. Most research in conservation biology involves the use of genetic resources, whenever organisms are being studied. As a type of conservation biology that focuses on genetic information detached from material organisms, conservation genetics raises issues comparable to the controversial examples discussed above. In this field, researchers study, for instance, deleterious effects of inbreeding, loss of genetic diversity, accumulation of deleterious mutations, genetic adaptation and many other genetic phenomena to gain a better understanding of which genetic factors may play a role in the extinction risk of a species and how such risks can be minimised (Frankham et al., 2010: pp8ff). More recently, genomic approaches have also found their way into conservation biology (McMahon et al., 2014; Shafer et al., 2015). Interestingly, genetic diversity within species is also a direct and specific target of biological conservation, to which the CBD explicitly refers in its definition of 'biological diversity'. The importance of this aspect of biodiversity is recognised in the strategic plan of the CBD in Aichi Target 13, which states that the genetic diversity of domesticated, farmed and other socio-economically and culturally valuable species should be safeguarded, and their genetic erosion minimised..$^{15}$ Besides conservation genetics and genomics the controversial examples of using genetic resources introduced above, eDNA and synthetic biology, could also play a role in conservation biology. Environmental DNA could serve as a tool to monitor biodiversity (Thomsen \& Willerslev, 2015), and it has been suggested that synthetic biology could, for instance, be used to introduce resistance to biological threats for endangered species or to control invasive species (Redford et al., 2013). DNA barcoding is another tool that involves digital sequences and is directly used to monitor genetic diversity and in conservation genetics research. These barcodes consist of short digital DNA sequences, by which species can be rapidly identified (e.g.,Bruford et al., 2017; Hebert et al., 2003; http://www.ibol.org (accessed December 2017). The use of direct genetic information, which may be detached from the original organism, thus becomes increasingly influential in conservation biology as well and may lead to controversy as to whether this should count as using genetic resources and whether it should be subject to ABS regulation.

\footnotetext{
15 For the Aichi Biodiversity Targets see: https://www.cbd.int/sp/targets/default.shtml (accessed December 2017)
} 


\section{Genetic resources and intellectual property rights}

Whether IPR and the idea of ABS can and should be combined has been controversially discussed. Concerns that the CBD could weaken IPR were reported as one of the main reasons why the US administration did not sign it in 1992 (Gepts, 2004; McManis, 1998). However, other authors have suggested that the idea of ABS is compatible with IPR (Gepts, 2004; McManis, 1998), or that, if implemented intelligently, IPR can complement the CBD's aims by providing incentives for biodiversity conservation (Lawson, 2009; Ruiz Muller, 2015; Stone, 1995; Vogel, 1994). The practical connection between ABS and IPR is that potential profits resulting from IPR related to genetic resources are amongst the central benefits to be negotiated in ABS. The reason to address the relation between $\mathrm{ABS}$ and IPR in this analysis of the concept of genetic resources is that the role of IPR in this discussion is linked to the particular features of genetic resources described above. The connection between genetic resources and IPR may at first seem like a paradox. How can something be discussed at the same time as a natural resource and as an object of IPR, such as patents, which are traditionally issued explicitly for something that is not natural but a human invention? This chapter seeks to address this apparent paradox and to show why IPR came to play such an important role in the debate and legislation surrounding genetic resources.

\subsection{Property rights for information}

Let us start with the very general question of what kind of property rights are appropriate for genetic resources. Such rights would have to consider the non-tangible informational nature of this type of resource. Information can be multiplied and used in different material and non-material forms without the knowledge of the provider. It is thus in the very nature of genetic resources that they are non-rivalrous, meaning that the utilisation of genetic resources by one does not hinder others from using them. Access to genetic resources cannot be regulated by property rights over material supplies. If we thus want to assign property or control rights over genetic resources, a new type of rights for natural information is needed. This could be a general agreement that providers of genetic resources have a right to exclude others from using 'their' natural information or to sell licences that allow its utilisation. The challenge of regulating access to information is well-known from intellectual contributions, where IPR are assigned to inventors to warrant compensation for their non-tangible input. To emphasise this connection, Vogel and Ruiz Muller speak of homology rather than analogy between natural and artificial information when it comes to their benefits and value (Ruiz Muller, 2015). Vogel thus suggests protecting providers of genetic resources with rights equivalent to IPR (Vogel, 1994, p: 38). ${ }^{16}$ While the discussion of property rights in the context of the CBD focuses on biodiversity, the earlier analysis of human genetic resources as a type of genetic resources suggests that in this context too, a system of property or control rights over natural genetic information is needed. Because of the absence of such a system in the context of the human genome, the gap of providing authority over genetic information to exclude others has been filled with the only type of property rights over information that has been established so far, namely with IPR in the form of gene patents. However, there are good arguments against IPR as a scheme to attribute rights over natural genetic sequences. Patents and other IPR are justified as rewards for inventions that are characterised as useful, novel and non-

\footnotetext{
16 Sometimes, Vogel refers to "intellectual property rights over genetic resources“ (Vogel, 1994: pp 31, 37). However, in the context of his book, this phrase can be understood as rights equivalent to IPR (as he writes on $\mathrm{p} 38$ ) rather than direct IPR over natural genetic information such as gene patents.
} 
obvious, which are criteria that cannot be attributed to natural information. This tension relates to the paradox mentioned at the start of this chapter and has been the source of criticism of gene patents in context of the human genome. Critics have reasonably argued that natural genetic sequences should count as discoveries rather than patentable inventions (Gold, 2012; Nuffild Council on Bioethics, 2002; Sagoff, 2004). ${ }^{17}$ Control rights over natural information would need to be justified based on other criteria than IPR, analogous to traditional property rights over material natural resources.

The first reason why IPR are so important in the context of genetic resources is thus pragmatic: IPR are the only type of property rights over information that have been established to date. However, since IPR have been designed for intellectual information, which raises very different claims than can be brought forward in the context of natural genetic resources, it seems to be inappropriate to assign IPR for natural genetic information itself.

\subsection{The importance of intellectual input}

The second reason for the important role of IPR in the discussion on genetic resources relates to the previously described diversity aspect and the partially potential nature of the value of genetic resources (see section 4). Together, these factors result in the need for a large investment of intellectual input to produce benefits. As biodiversity, genetic resources are characterised by a wide variety of different organisms, compounds and sequences with potential value. Identifying and using the actual value within this diversity requires an independent research and development procedure for each element used. It can be countered that intellectual input also plays a role in the context of other types of natural resource since, for instance, the development of motors that process petrol or the utilisation of rare earths in mobile phones also depended on human inventions. However, it is argued here that more of this type of human contribution is usually necessary in the case of genetic resources because of the diversity aspect and the partially potential nature of their value. Profits from genetic resources as natural resources are thus highly dependent on intellectual input. This tendency is reinforced by the fact that the utilisation of these resources is by no means obvious but highly dependent on extensive research processes and inventive steps. This is in contrast to biological resources such as fisheries or timber, where users directly consume the raw material, or resources such as diamonds or ores, where the raw material is of high cultural value and its processing relatively straightforward and obvious.

\subsection{Resolving the paradox: close connection between natural and intellectual contribution} At the beginning of this chapter, the question was raised as to whether the discussion of genetic resources as a type of natural resource and at the same time a subject of IPR involves a paradox. As discussed, the case of gene patents, where it is the natural contribution (gene sequence) itself that has been patented, may indeed be paradoxical in this sense and thus highly questionable. However, the previous chapter shows why IPR are so closely interwoven with genetic resources even when no gene patents are involved. According to this line of argumentation, IPR should not be understood as property rights over genetic resources as natural information, but over the intellectual input required to make use of this natural information. It is thus justifiable that

17 In accordance with these arguments, the United States Supreme Court decided in a much-noticed court case concerning patents of Myriad Genetics, Inc. on the BRCA1 and BRCA2 genes 2013, that natural gene sequences are not patentable (e.g., Kesselheim et al., 2013). 
inventors are compensated for their intellectual contribution to the product.

Nevertheless, it can be reasonably argued that they should also pay for the natural information from which they benefited because they did not have any particular claims on this information, which they received and used for free. ${ }^{18}$ One widely discussed option to acknowledge this natural contribution is the idea of requesting disclosure of origin in IPR applications, which would trigger the duty to share benefits with the providers of this natural information in case of revenue from royalties (e.g., Ruiz Muller, 2015; Sarnoff \& Correa, 2006; WIPO, 2004). Several countries have already implemented such disclosure requirments in their IPR legislation (WIPO, 2017). Henry Vogel and Manuel Ruiz Muller have suggested "bounded openness", a particular model taking up this idea (Ruiz Muller, 2015 chapters 4,5). This model suggests that natural information should flow freely (openness) until revenue is made from intellectual property (boundedness), in which case the requirement to disclose the use of genetic resources in IPR applications would trigger the duty to share benefits. Besides this particular model of benefit sharing, the bounded openness model is characterised by the idea of a multilateral regime, which acknowledges oligopoly rights of all states with incidences of the genetic resource in question rather than monopoly rights of singular states.

The nexus between natural and human contribution is particularly close in the case of crops (key example 1), which were described earlier as 'non-natural' or 'not purely natural', because both the natural and human contribution have formed the plant species in its current state. Again, this particular situation may justify a special type of regulation such as what is already in place with plant breeders' rights.

\section{Summary and conclusion}

This analysis of 'genetic resources' is based on a biological interpretation of the concept and an enquiry of how genetic resources are being used and where their value occurs in practice. The resulting understanding of genetic resources as an informational type of natural resource points out that the CBD's definition of 'genetic resources', which refers to their material, is not consistent with how genetic resources are actually being used and valued. However, it is argued here that the NP's definition of utilisation of genetic resources as working with the "genetic and/or biochemical composition of genetic resources" allows consideration of the informational nature of this type of resources in the current regulatory framework.

The article aimed to develop a coherent, consistent and comprehensive analysis of this concept with six practical examples of genetic resource utilisation (three classical examples, two controversial examples and a biodiversity example). It introduced genetic resources as a particular type of natural resource and related this discussion to the notion of genetic resources as an appreciation of biodiversity. Moreover, the article attempted to explain the important role of IPR in the discussion of genetic resources with reference to their informational nature as well as the diversity and potentiality of value in this type of natural resource, which is expressed in the connection to biodiversity.

\footnotetext{
18 The idea that there should be compensation for the use of natural genetic resources does not depend on the idea of national sovereignty over genetic resources, according to which it is the states in which the respective genetic resources can be found that should be compensated. Instead, cosmopolitans for whom some benefits of any type of natural resource should be shared globally, or environmentalists who state that some of the profits from nature should go back into the protection of nature, could also support the idea of compensation for the use of natural genetic resources.
} 
Furthermore, it has been shown that the exclusion of human genetic resources and the inclusion of biological human products such as crops in the regulation of genetic resources cannot be explained solely from the general analysis of the biological function of genetic resources and how they are actually being used and valued. The reasons to exclude human genetic resources and include crops in the regulatory scheme are of a specific nature, meaning that human genetic resources are not excluded because they are not a type of genetic resources but because they raise particular issues that must be regulated separately. In this sense, the article argues that in the case of other controversial uses of genetic resources, such as the use of digital sequences, the question of whether or not they should be included in the regulatory framework also cannot be reduced to the question of whether they are a form of using genetic resources. Instead, specific implications of putting these resources under an ABS scheme must also be considered.

One of the main objectives of this article is bringing the discussion of the concept of 'genetic resources' closer to the conservation biology community. The current discourse focuses on the legal and economic implications and interpretation of this concept. However, since the subject is a biological one and biodiversity conservation was the trigger for the development of this concept in the first place, it is also important that researchers and practitioners in the field of conservation biology contribute to discussion regarding the questions: "What are genetic resources?" and "How should they be regulated?". Conservation biologists can provide an inside view on what it means to utilise genetic resources. In return, the development of a thorough understanding of the relation between biodiversity, natural resources and IPR in the concept of 'genetic resources' is important for designing coherent and consistent biodiversity conservation strategies.

\section{Acknowledgements}

This work was supported by the UZH Research Priority Program (URPP) on 'Global Change and Biodiversity'. I am grateful to the members of this interdisciplinary research consortium for inspiring discussions, which indicated the need for a basic analysis of the concept of 'genetic resources'. In particular, I would like to thank Peter Schaber, Jack R. Williams, Michael Schaepman and Cornelia Krug for their helpful comments and suggestions on previous versions of the manuscript. Finally, I would like to thank two anonymous reviewers for their constructive comments.

\section{References}

Baglay, M. A. (2015). Digital DNA: The Nagoya Protocol, Intellectual Property Treaties, and Synthetic Biology. Wilson Center, Available at: http://www.synbioproject.org/publications/digital-dna-nagoya-protocol/ (accessed December 2017)

Baglay, M. A., \& Rai, A. K. (2013). The Nagoya Protocol and Synthetic Biology Research: A Look at the Potential Impacts. Wilson Center, Available at: https://www.wilsoncenter.org/publication/the-nagoya-protocol-and-syntheticbiology-research-look-the-potential-impacts (accessed December 2017)

Baird, D. J., \& Hajibabaei, M. (2012). Biomonitoring 2.0: a new paradigm in ecosystem assessment made possible by next-generation DNA sequencing. Molecular Ecology, 21, 3039-2044. doi:10.1111/j.1365-294X.2012.05519.x

Bruford, M. W., Davies, N., Dulloo, M. E., Faith, D. P., \& Walters, M. (2017). Monitoring Changes in Genetic Diversity. In M. Walters \& R. Scholes (Eds.), The GEO Handbook on Biodiversity Observation Networks (pp. 107-128): Springer Open. 
CBD, Secretariat of the Convention on Biological Diveristy (2008). UNEP/CBD/WG$\mathrm{ABS} / 7 / 2,12.12 .2008$. Availabla at: https://www.cbd.int/doc/meetings/abs/abswg-07/official/abswg-07-02-en.pdf (accessed December 2017).

Dauda, B., \& Dierickx, K. (2013). Benefit sharing: an exploration on the contextual discourse of a changing concept. BMC Medical Ethics, 14(36), 1-8. doi:10.1186/1472-6939-14-36

Deiner, K., Fronhofer, E. A., Machler, E., Walser, J. C., \& Altermatt, F. (2016). Environmental DNA reveals that rivers are conveyer belts of biodiversity information. Nat Commun, 7, 12544. doi:10.1038/ncomms12544

De Jonge, B. (2011). What is Fair and Equitable Benefit-sharing? J. Agric Environ Ethics, 24, 127-146. doi:10.1007/s10806-010-9249-3

Deplazes, A. (2009). Piecing together a puzzle. An exposition of synthetic biology. EMBO Rep, 10(5), 428-432. doi:10.1038/embor.2009.76

Deplazes-Zemp, A. (2018). Commutative Justice and Access and Benefit Sharing for Genetic Resources Ethics, Policy \& Environment. doi:10.1080/21550085.2018.1448042

Frankham;, R., Ballou;, J. D., Briscoe;, D. A., \& McInnes, K. H. (2010). Introduction to conservation genetics. Cambridge: Cambridge University Press.

Gepts, P. (2004). Who Owns Biodiversity, and How Should the Owners Be Compensated? Plant Physiology, 134, 1295-1307. doi:10.1104/pp.103.038885

Gold, R. E. (2012). Patenting of Genes: Discoveries or Inventions? eLS (Encyclopedia of Life Sciences). doi:10.1002/9780470015902.a0005183.pub2

Gross, T. (2014). National Study on ABS Implementation in Brazil. ABS Capacity Development Initiative, abailable at: http://www.absinitiative.info/fileadmin/media/Knowledge_Center/Pulications/ABS_Dialogue_0 42014/National_study_on_ABS_implementation_in_Brazil_20140716.pdf (accessed December 2017).

Harlan, J. R. (1975). Our Vanishing Genetic Resources. Science, 188, 618-621.

Harvey, A. L., \& Gericke, N. (2011). Bioprospecting: Creating a Value for Biodiversity. In I. Y. Pavlinov (Ed.), Research in Biodiversity - Models and Applications (pp. 323-338). Rijeka: InTech.

Hebert, P. D. N., Cywinska, A., Ball, S. L., \& DeWaard, J. R. (2003). Biological identifications through DNA barcodes. Proceedings of the Royal Society BBiological Sciences, 270(1512), 313-321. doi:10.1098/rspb.2002.2218

ICSWGSB, International Civil Society Working Group On Synthetic Biology (2016). Synthetic Biology and the CBD, Five key decisins for COP 13 ] COP-MOP 8. Available at: https://www.boell.de/en/2016/11/02/synthetic-biology-and-cbdfive-key-decisions-cop-13-cop-mop-8 (accessed December 2017).

Kamau Evanson, C., \& Winter, G. (2009). Genetic resources, traditional knowledge, and the law: solutions for access and benefit sharing. London: Earthscan.

Kesselheim, A. S., Cook-Deegan, R. M., Winickoff, D. E., \& Mello, M. M. (2013). Gene patenting-the Supreme Court finally speaks. N Engl J Med, 369(9), 869-875. doi:10.1056/NEJMhle1308199

Kingston, D. G. I. (2011). Modern Natural Products Drug Discovery and Its Relevance to Biodiversity Conservation. Journal of Natural Products, 74, 496-511. doi:10.1021/np100500t

Lawson, C. (2009). The role of patents in biodiversity conservation. Nature biotechnology, 27(11), 994-995. doi:10.1038/nbt1109-994 
Maier, D. S. (2013). What's So Good About Biodiversity? A Call for Better Reasoning About Nature's Value. Dordrecht: Springer.

Manheim, B. S. (2016). Regulation of synthetic biology under the Nagoya Protocol. Nature biotechnology, 34(11), 1104-1105. doi:10.1038/nbt.3716

McMahon, B. J., Teeling, E. C., \& Hoglund, J. (2014). How and why should we implement genomics into conservation? Evolutionary Applications, 7(9), 999-1007. doi:10.1111/eva.12193

McManis, C. R. (1998). The Interface Between International Intellectual Property and Environmental Protection: Biodiversity and Biotechnology. Washington University Law Review, 76(1), 255-279.

Mooney, P. (1983). The Law of the Seed - Another Development and Plant Genetic Resources. Available at: http://www.daghammarskjold.se/publication/law-seedanother-development-plant-geneticresources/ (accessed December 2017).

Moore, M. (2015). A Political Theory of Territory. Oxford: Oxford University Press.

Nuffild Council on Bioethics (2002). The ethics of patenting DNA, a discussion paper. Available at: http://nuffieldbioethics.org/wp-content/uploads/2014/07/Theethics-of-patenting-DNA-a-discussion-paper.pdf (accessed December 2017).

Oberthür, S., \& Rosendal, K. G. (2013). Global governance of genetic resources, Background and analytical framework. In S. Oberthür \& K. G. Rosendal (Eds.), Global Governance of Genetic Resources, Access and benefit sharing after the Nagoya Protocol (pp. 1-17). New York, London: Routledge.

Oduardo-Sierra, O., Hocking, B. A., \& Vogel, J. H. (2012). Monitoring and Tracking the Economics of Information in the Convention on Biological Diversity: Studied Ignorance (2002-2011). Journal of Politics and Law, 5(2), 29-39.

Posey, D., A. (1995). Indigenous Peoples and Traditional Resource Rights: A Basis for Equitable Relationships? Oxford: Green College Centre for Environmental Policy and Understanding, Available at: https://www.iccaconsortium.org/wpcontent/uploads/2015/08/example-ip-and-traditional-resource-rights-addisonposey-1995-en.pdf (accessed December 2017)

Redford, K. H., Adams, W., \& Mace, G. M. (2013). Synthetic biology and conservation of nature: wicked problems and wicked solutions. PLoS Biol, 11(4), e1001530. doi:10.1371/journal.pbio.1001530

Reid, J. (2009). Biopiracy: The struggle for traditional knowledge rights. American Indian Law Review, 34(1), 77-98.

Robinson, D. F. (2014). Biodiversity, Access and Benefit-Sharing, Global Case Studies. London: Routledge.

Ruiz Muller, M. (2015). Genetic Resources as Natural Information, Implications for the Convention on Biological Diversity and Nagoya Protocol. London, New York: Earthscan, Routledge.

Sagoff, M. (2004). Are Genes Inventions? An Ethical Analysis of Gene Patents. In J. Burley \& J. Harris (Eds.), A Companion to Genethics: Blackwell Publishing.

Sarnoff, J. D., \& Correa, C. M. (2006). Analysis of Options for Implementing Disclosure of Origin Requirements in Intellectual Property Applications. United Nations Conference on Trade and Development, Available at: http://unctad.org/en/docs/ditcted200514_en.pdf (accessed December 2017).

Schindel, D. E. (2010). Biology without borders. Nature, 467(7317), 779-781. doi:10.1038/467779a

Schroeder, D., \& Lasen-Diaz, C. (2006). Sharing the benefits of genetic resources: from biodiversity to human genetics. Dev World Bioeth, 6(3), 135-143. doi:10.1111/j.1471-8847.2006.00148.x 
Schroeder, D., \& Pogge, T. (2009). Justice and the Convention on Biological Diveristy. Ethics \& International Affairs, 23(3), 267-280. doi:10.1111/j.17477093.2009.00217.x

Schuklenk, U., \& Kleinsmidt, A. (2006). North-South benefit sharing arrangements in bioprospecting and genetic research: a critical ethical and legal analysis. Dev World Bioeth, 6(3), 122-134. doi:10.1111/j.1471-8847.2006.00149.x

Shafer, A. B. A., Wolf, J. B. W., Alves, P. C., Bergstrom, L., Bruford, M. W., Brannstrom, I., .. . Zielinski, P. (2015). Genomics and the challenging translation into conservation practice. Trends in Ecology \& Evolution, 30(2), 78-87. doi:10.1016/j.tree.2014.11.009

Stone, C. D. (1995). What to Do About Biodiversity: Property Rights, Public Goods, and the Earth's Biological Riches. Southern California Law Review, 68(3), 577-620.

Thomsen, P. F., \& Willerslev, E. (2015). Environmental DNA - An emerging tool in conservation for monitoring past and present biodiversity. Biological Conservation, 183, 4-18. doi:10.1016/j.biocon.2014.11.019

Tvedt, M. W., \& Schei, P. J. (2013). The term 'genetic resources' Flexible and dynamic while providing legal certainty? In S. Oberthür \& K. G. Rosendal (Eds.), Global Governance of Genetic Resources, Access and benefit sharing after the Nagoya Protocol (pp. 18-32). New York, London: Routledge.

Vogel, J. H. (1994). Genes for Sale, Privatization as a Conservation Policy. New York, Oxford: Oxford University Press.

Vogel, J. H., Álvarez-Berríos, N., Quiñones-Vilches, N., Medina-Muñiz, J. L., Pérez-Montes, D., Arocho-Montes, A. I., ... Santiago-Ríos, J. (2011). The Economics of Information, Studiously Ignored in the Nagoya Protocol on Access to Genetic Resources and Benefit Sharing. Law, Environment and Development Journal, 7(1), 52-65.

WIPO, W. I. P. O. (2004). WIPO Technical Study on Patent Disclosure Requirements Related to Genetic Resources and Traditional Knowledge, Available at http://www.wipo.int/edocs/pubdocs/en/tk/786/wipo_pub_786.pdf (accessed December 2017).

WIPO, W. I. P. O. (2017). Key Questions on Patent Disclosure Requirements for Genetic Resources and Traditional Knowledge, Availabla at http://www.wipo.int/edocs/pubdocs/en/wipo_pub_1047.pdf (accessed December 2017). 